\title{
Penerapan Arsitektur Kontekstual Dalam Perancangan Kawasan Wisata Budaya Samin Di Blora
}

\author{
Novitasari Rahayuningtyas ${ }^{1 *}$, Tri Joko Daryanto ${ }^{2}$, Ofita Purwani ${ }^{3}$ \\ Program Studi Arsitektur, Fakultas Teknik, Universitas Sebelas Maret ${ }^{1}$ \\ Email: novitasarirahayuningtyas@gmail.com ${ }^{*}$ \\ Program Studi Arsitektur, Fakultas Teknik, Universitas Sebelas Maret ${ }^{2}$ \\ Program Studi Arsitektur, Fakultas Teknik, Universitas Sebelas Maret ${ }^{3}$
}

\begin{abstract}
Samin culture is one of the national heritage which is based on Samin's tradition. The community of Samin is spread over some areas, one of them is Klopoduwur village, Blora. The uniqueness of Samin culture is the traditions, daily activities, and artifacts. Local government has decided to develope tourism in this village, which is reasonable in regard to its potentials. Tourism can help the economy of Samin people while at the same time induce its cultural activities. The Samin village, then, is designed by adding the tourism and culture facilities, also public infrastructures for the tourists and its society. Contextual architecture is applied in the design of the area, by applying visual elements to the old buildings and environment into the new buildings, to get the look which familiar for the Samin's society, and also to get the authentic look for the tourists.
\end{abstract}

Keywords: Samin culture, Contextual, Tourism, Visual continuity, Tradition

\section{PENDAHULUAN}

Budaya Samin memiliki potensi yang layak untuk diangkat sebagai destinasi wisata budaya. Potensi tersebut antara lain ajaran sebagai dasar budaya, keseharian warga, kerajinan dan pertunjukan, serta keasrian lingkungan dan arsitektur. Ajaran Samin merupakan sebuah gerakan meditasi yang mengerahkan kekuatan batiniah guna menguasai hawa nafsu. Prinsip pokok ajaran Samin menyangkut nilai kehidupan manusia sebagai pedoman bersikap dan tingkah laku, agar selalu hidup dengan baik dan jujur Komunitas Samin percaya, dengan melaksanakan ajaran yang mengutamakan keujuran dan kesederhanaan, mereka akan terlepas dari hukum alam atau hukum karma. Salah satu wilayah di Blora yang menerima ajaran tersebut adalah Desa Klopodhuwur dengan pusat ajaran di Dukuh Karangpace. Warga Dukuh Karangpace merupakan komunitas Samin yang paling memegang teguh ajaran Samin, dengan pola keseharian yang masih tradisional di Kabupaten Blora.

Mulai akhir tahun 2016, Dukuh Karangpace yang merupakan pemukiman komunitas Samin tengah dilirik berbagai kalangan sebagai destinasi wisata budaya. Tak hanya kalangan seniman dan budayawan, akademisi juga mulai banyak melirik Kampung Samin sebagai salah satu kekayaan budaya di Blora. Salah satu upaya Pemerintah Daerah Blora adalah menetapkan Desa Klopodhuwur sebagai desa wisata, yang tertulis dalam Rencana Induk Pengembangan Pariwisata Daerah Kabupaten Blora Tahun 2014-2028, dan Peraturan Daerah Kabupaten Blora Nomor 18 Tahun 2011, Tentang Rencana Tata Ruang Wilayah Kabupaten Blora Tahun 2011-2031.

Fasilitas wisata budaya yang direncanakan Pemerintah Daerah Kabupaten Blora untuk Kawasan Samin adalah museum, perpustakaan, dan toko souvenir (BAPPEDA Kabupaten Blora, 2015). Namun fasilitas tersebut hanya mewadahi kegiatan yang bersifat pameran dan pustaka. Berdasarkan survei di Dukuh Karangpace, wisatawan datang untuk melihat pola hidup masyarakat Samin yang masih tradisional, mempelajari ajaran-ajaran Samin yang mengajarkan tentang ketenangan, kejujuran dan kesederhanaan, serta meneliti budaya Samin, dengan kata lain wisatawan mencari sesuatu yang 'otentik' tentang Samin. 
Maka dari itulah fasilitas wisata budaya yang direncanakan harus mencakup seluruh kegiatan tersebut, mengingat hingga sekarang belum tersedia fasilitas yang memadai di kawasan Samin.

Otentisitas atau keaslian suatu daerah, dari segi visual dapat dilihat dari lingkungan fisik dan bentuk-bentuk lokal yang terdapat di dalam daerah tersebut. Dalam perancangan Kawasan Wisata Budaya Samin keaslian sangat diutamakan, cara untuk mendapatkan keaslian tersebuat yaitu, dengan mendesain bangunan/fasilitas baru yang mirip mungkin dengan bangunan lama. Terdapat tiga cara untuk meningkatkan atau menciptakan kembali keaslian pada suatu daerah. Pertama, dengan menggunakan sejarah landscape dalam artian mempertahankan ikon budaya, seperti gaya arsitektur, tipologi bangunan dan konfigurasi spasial. Kedua, memperbarui kembali citra dahulu yang sudah lama hilang. Citra dapat berupa visual maupun suasana, yaitu mengembalikan keadaan lingkungan dan suasana asli daerah tersebut. Ketiga, membuka tempat-tempat yang memiliki sejarah atau temat-tempat yang memiliki arti penting (Alsayyad, 2001).

Arsitektur Kontekstual merupakan suatu perencanaan dan perancangan arsitektur, yang memperhatikan permasalahan kontinuitas visual antar bangunan baru dengan nuansa lingkungan yang ada di sekitarnya, dan melakukan studi terhadap kesulitan-kesulitan yang timbul dalam menciptakan keserasian antar bangunan yang berbeda jaman dan gaya, dalam suatu lokasi yang berdekatan (Brolin, 1980). Keterkaitan visual antara bangunan baru dengan lingkungan terdekat dapat dibentuk melalui aspek-aspek pembentuk bangunan. Lingkungan merupakan bangunan terdekat, gaya tradisional, dan landmark sedangkan aspek pembentuk bangunan dan lingkungan ada dua yaitu aspek visual umum dan nilai sejarah. Kontinuitas visual mengarah pada keserasian elemen visual, maka Arsitektur Kontekstual diterapkan dengan memasukkan elemen-elemen visual yang terdapat pada bangunan maupun lingkungan ke dalam bangunan baru yang direncanakan. Elemen visual bangunan tersebut antara lain jarak, komposisi, ketinggian, proporsi, bentuk, material, warna, dan skala yang termasuk dalam tipologi bangunan dan gaya arsitektur. Arsitektur kontekstual juga memperhatikan nilai sejarah yang mendasari suatu bentuk bangunan dan citra lingkungan, serta lebih fleksibel terhadap perkembanganan fungsi kegiatan pada bangunan karena lebih mengutamakan kontinuitas elemen visual pada desain yang dihasilkan, sehingga arsitektur kontekstual sesuai untuk diterapkan dalam perancangan kawasan Samin.

\section{METODE}

Metode yang digunakan dalam Kawasan Wisata Budaya Samin yaitu metode perencanaan dan metode perancangan.

Metode perencanaan merupakan langkahlangkah dalam merencanakan sistem atau kegiatan dalam Kawasan Wisata Budaya Samin. Berikut langkah-langkah perencanaan Kawasan Wisata Budaya Samin:

- Memaparkan definisi Kawasan Wisata Budaya Samin untuk mendapatkan pengertian objek yang dibangun

- Mencari preseden Kawasan Wisata Budaya untuk mendapatkan gambaran kegiatan maupun fasilitas kampung dan desa adat

-Mengidentifikasi Budaya Samin yang akan diangkat

-Menyusun kegiatan dan fasilitas berdasarkan kebutuhan wisata dan budaya Samin didukung gambaran kegiatan serta fasilitas pada preseden. Kegiatan dan fasilitas dikelompokkan berdasarkan fungsi kegiatan.

Metode perancangan merupakan langkahlangkah dalam merancang desain Kawasan Wisata Budaya Samin. Berikut langkah-langkah perancangan Kawasan Wisata Budaya Samin:

-Memaparkan teori-teori kontekstual untuk mendapatkan prinsip-prinsip arsitektur kontekstual yang digunakan sebagai pendekatan desain bangunan, untuk mendapatkan mendesain bangunan baru yang terlihat otentik.

-Mengidentifikasi elemen-elemen visual pada bangunan dan lingkungan Samin untuk diterapkan pada bangunan baru sebagai konsep tampilan.

-Menganalisis tapak berdasarkan kebutuhan dan keterkaitan kegiatan

-Menganalisis kebutuhan peruangan berdasarkan kegiatan, besaran ruang berdasarkan data kunjungan wisata, dan organisasi ruang berdasarkan fungsi dan komposisi ruang dalam lingkungan Samin.

-Menerapkan elemen-elemen visual Samin pada bangunan baru. 


\section{HASIL DAN PEMBAHASAN}

Hasil dan pembahasan meliputi kegiatan dan fasilitas, perancangan kawasan, perancangan bentuk, dan utilitas kawasan.

\subsection{Kegiatan dan Fasilitas}

Kegiatan dan Fasilitas dibedakan menjadi tiga menurut kelompok kegiatan dalam kawasan yaitu kegiatan utama, kegiatan pelengkap dan kegiatan pendukung. Kegiatan utama merupakan kegiatan budaya Samin yang dibagi menjadi dua sub kegiatan yaitu kegiatan adat dan kegiatan kerajinan, Kegiatan pelengkap merupakan kegiatan pariwisata, dan kegiatan pendukung merupakan kegiatan yang mendukung kegiatan pelengkap dan kegiatan pariwisata. Menurut pengguna dikelompokkan menjadi 3 yaitu untuk wisatawan, masyarakat setempat, serta wisatawan sekaligus masyarakat setempat.

Tabel 1. Jenis Kegiatan dan Fasilitas Kawasan Wisata Budaya Samin

\begin{tabular}{|c|c|c|c|}
\hline No. & Wisatawan & Penduduk & Fasilitas \\
\hline 1. & $\begin{array}{l}\text { Memarkir } \\
\text { kendaraan }\end{array}$ & - & Area Parkir \\
\hline 2. & $\begin{array}{l}\text { Menyewa } \\
\text { pemandu }\end{array}$ & - & $\begin{array}{l}\text { Pusat } \\
\text { Informasi }\end{array}$ \\
\hline 3. & $\begin{array}{l}\text { Mengelilingi } \\
\text { kawasan }\end{array}$ & \multirow[t]{2}{*}{$\begin{array}{l}\text { Beraktivitas } \\
\text { sehari-hari }\end{array}$} & \multirow[t]{2}{*}{$\begin{array}{l}\text { Kawasan } \\
\text { Samin }\end{array}$} \\
\hline 4. & $\begin{array}{l}\text { Meneliti budaya } \\
\text { Samin }\end{array}$ & & \\
\hline \multirow[t]{2}{*}{5.} & \multirow{2}{*}{$\begin{array}{l}\text { Mempelajari } \\
\text { ajaran Samin }\end{array}$} & \multirow[t]{2}{*}{-} & Pendapa \\
\hline & & & Perpustakaan \\
\hline 6. & - & $\begin{array}{l}\text { Musyawarah, } \\
\text { perkumpulan }\end{array}$ & Pendapa \\
\hline 7. & $\begin{array}{l}\text { Melihat } \\
\text { pertunjukan dan } \\
\text { upacara adat }\end{array}$ & $\begin{array}{l}\text { Melaksanakan } \\
\text { upacara adat dan } \\
\text { menggelar } \\
\text { pertunjukan }\end{array}$ & $\begin{array}{l}\text { Pendapa dan } \\
\text { halaman } \\
\text { pendapa }\end{array}$ \\
\hline 8. & - & $\begin{array}{l}\text { Mempersiapkan } \\
\text { upacara } \\
\text { adat/pertunjukan }\end{array}$ & $\begin{array}{l}\text { Balai } \\
\text { Persiapan }\end{array}$ \\
\hline 9. & - & $\begin{array}{l}\text { Bertapa, } \\
\text { berkumpul }\end{array}$ & $\begin{array}{l}\text { Situs } \\
\text { Prapatan }\end{array}$ \\
\hline 10. & $\begin{array}{l}\text { Belajar membuat } \\
\text { tikar pandan }\end{array}$ & $\begin{array}{l}\text { Membuat } \\
\text { kerajinan tikar } \\
\text { pandan }\end{array}$ & \multirow[t]{2}{*}{$\begin{array}{l}\text { Sentra } \\
\text { Kerajinan } \\
\text { Samin }\end{array}$} \\
\hline 12. & $\begin{array}{l}\text { Belajar membuat } \\
\text { batik }\end{array}$ & $\begin{array}{l}\text { Membuat } \\
\text { kerajinan Batik } \\
\text { Samin }\end{array}$ & \\
\hline \multirow[b]{2}{*}{13.} & \multirow[t]{2}{*}{ Belajar bertani } & \multirow[t]{2}{*}{ Bertani } & Rumah Bibit \\
\hline & & & Saung \\
\hline 14. & Belajar beternak & $\begin{array}{l}\text { Memelihara } \\
\text { ternak }\end{array}$ & $\begin{array}{l}\text { Kandang } \\
\text { Ternak } \\
\text { Terpadu } \\
\end{array}$ \\
\hline 15. & Menginap & & $\begin{array}{l}\text { Penginapan } \\
\text { Wisatawan } \\
\text { Samin }\end{array}$ \\
\hline 16. & $\begin{array}{l}\text { Membeli souvenir } \\
\text { khas Samin }\end{array}$ & $\begin{array}{l}\text { Menjual souvenir } \\
\text { khas Samin }\end{array}$ & $\begin{array}{l}\text { Toko } \\
\text { Souvenir }\end{array}$ \\
\hline
\end{tabular}

Tabel 1. Jenis Kegiatan dan Fasilitas Kawasan Wisata Budaya Samin

\begin{tabular}{|c|l|l|l|}
\hline No. & Wisatawan & \multicolumn{1}{c|}{ Penduduk } & Fasilitas \\
\hline 16. & $\begin{array}{l}\text { Membeli souvenir } \\
\text { khas Samin }\end{array}$ & $\begin{array}{l}\text { Menjual souvenir } \\
\text { khas Samin }\end{array}$ & $\begin{array}{l}\text { Toko } \\
\text { Souvenir }\end{array}$ \\
\hline 17. & $\begin{array}{l}\text { Membeli makanan } \\
\text { khas Samin }\end{array}$ & $\begin{array}{l}\text { Menjual makanan } \\
\text { khas Samin }\end{array}$ & $\begin{array}{l}\text { Rumah } \\
\text { Makan }\end{array}$ \\
\hline 18. & MCK & - & WC umum \\
\cline { 3 - 4 } & & $\begin{array}{l}\text { WC umum } \\
\text { baru }\end{array}$ \\
\hline 19. & Beribadah & - & Musholla \\
\hline
\end{tabular}

Keterangan :

\begin{tabular}{|l|l|}
\hline & Kegiatan Utama \\
\hline & Kegiatan Pelengkap \\
\hline & Kegiatan Pendukung \\
\hline & Fasilitas Lama \\
\hline & Fasilitas Baru \\
\hline
\end{tabular}

\subsection{Perancangan Kawasan}

1. Pencapaian, Perletakan Parkir, dan SirkulasiPencapaian Kawasan dapat melalui dua arah pertama dari arah Utara (Pusat Kota Blora) dan arah Selatan (Kecamatan Randhublatung). Persentase kendaraan terbesar berasal dari arah pusat kota sehingga ME diletakkan di sisi Utara. Pengunjung dapat memasuki kawasan melalui tiga jalan lokal yang munghubungkan pemukiman Samin dengan Jalan Raya. Jalan lokal 3 merupakan jalur yang paling dekat dengan arah kedatangan pengunjung, kemungkinan sebagian besar pengunjung akan menggunakan jalan lokal 3, sehingga jalan lokal 3 menjadi jalur masuk dan keluar utama dari area pemukiman.

Area parkir tidak berada dalam area kawasan untuk mencegah kendaraan masuk dan perubahan tatanan lingkungan, maka area parkir diletakkan pada sisi Timur jalan Raya BloraRandhublatung, agak ke Utara. Pada area parkir juga terdapat halte untuk pengunjung yang menggunakan kendaraan umum.

Sirkulasi dibedakan menjadi dua yaitu sirkulasi dalam dan sirkulasi luar kawasan. Sirkulasi luar diperuntukkan untuk pengguna kendaraan dan sirkulasi dalam diperuntukkan untuk pejalan kaki. 


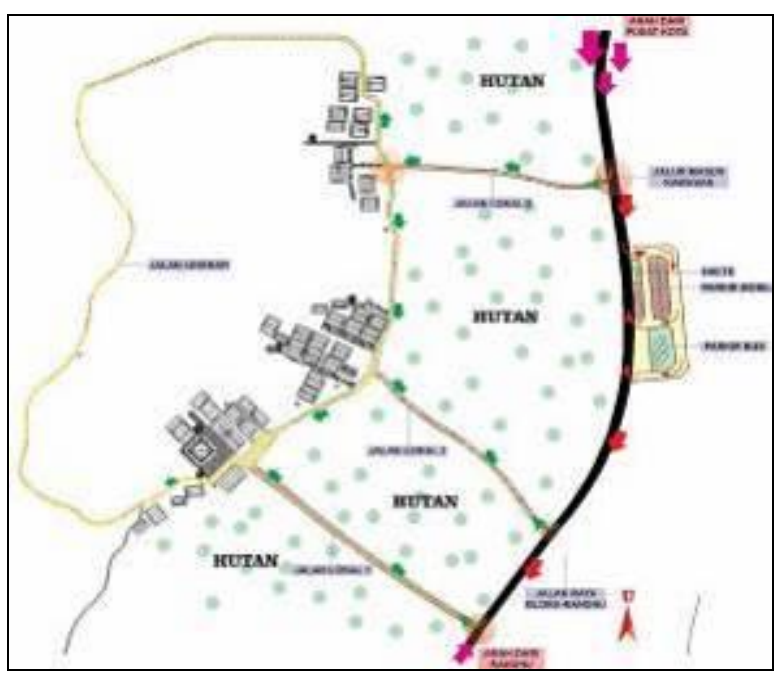

Gambar 1. Pencapaian, Sirkulasi, dan Perletakan Parkir Sumber : Dokumen Novita, 2017

2. Lansekap Kawasan

Lansekap kawasan berdasar pada citra tertutup dan sederhana, tetapi tetap menarik sebagai kawasan wisata. Citra tertutup dicapai dengan mempertahankan topografi kawasan sehingga pemukiman tidak terlihat dari jalan raya. Citra sederhana dicapai dengan mempertahankan konfigurasi spasial kawasan, bentuk dasar dan material lama yang memiliki komposisi dan bentuk sederhana. Citra menarik dicapai dengan penambahan elemen-elemen pembentuk citra yang berkarakter Samin pada kawasan. Elemen-elemen tersebut antara lain:

Jalanan kampung pada kawasan dirapikan dan diperbaiki, serta menggunakan material yang lebih keras agar tidak becek ketika hujan. Desain jalan kampung tetap menggunakan material lokal, yaitu batu pada bagian tengah dan diapit oleh beton untuk menjaga posisi batu agar tidak bergeser.

Ruang publik diletakkan pada area penghubung antar zona, sebagai area interaksi dan memperjelas batas antar cluster. Desain Ruang publik menyerupai pendhapa kecil dengan atap bekok lulang, dinding terbuka agar lebih menyatu dengan alam, dan lantai ruang publik agak tinggi.

Gapura diletakkan pada setiap jalur masuk dari jalan raya sebagai penanda jalur masuk. Desain gapura menggunakan atap bekok lulang sebagai ciri khas bangunan Samin untuk menandakan bahwa di situlah letak pemukiman Samin.

Titik pertemuan antara jalur masuk dan kawasan pemukiman ditambahkan pergola, sebagai tanda memasuki kawasan pemukiman. Desain pergola, menyerupai struktur pada atap pelana dengan material kayu jati ditambah dengan tanaman sulur.

Taman diletakkan pada seberang jalur masuk menuju pemukiman, untuk mendapatkan kesan lingkungan yang indah dan hijau. Vegetasi peneduh ditambahkan pada sisi-sisi jalan penghubung, dan vegetasi penghias diletkakkan pada area lorong dekat dengan rumah-rumah penduduk. Keseluruhan vegetasi yang digunakan merupakan tanaman lokal Samin seperti pohon jati, pohon kersen, pohon pisang, bambu, sulur dan bunga bougenville.

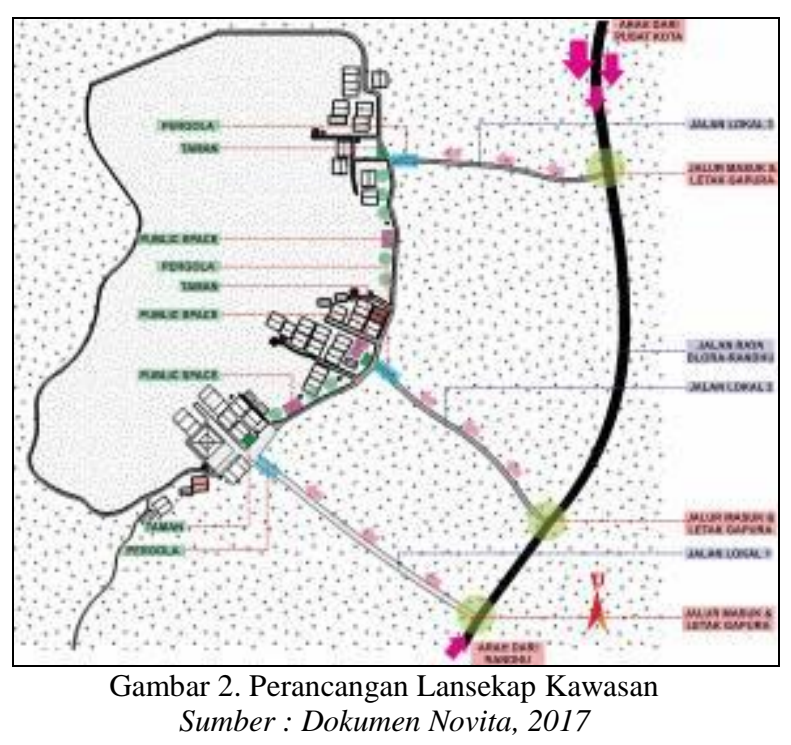

\section{Pembagian Zona}

Terdapat tiga cluster dalam Dukuh Karangpace, yang akan terbagi menjadi tiga zona utama. Setiap zona memiliki peranan kegiatan masingmasing. Zona pertama yaitu cluster satu merupakan zona adat sebagai pusat kegiatan ajaran dan upacara adat, yang berdasar pada letak pendhapa sebagai pusat ajaran dan rumah kepala adat di zona pertama. Zona kedua yaitu cluster dua merupakan zona karya sebagai pusat kegiatan kerajinan batik dan tikar pandan, yang berdasar pada letak rumah pembuat tikar pandan terdapat pada zona kedua. Zona ketiga yaitu cluster tiga merupakan zona transisi, yang diperuntukkan untuk kelompok kegiatan pelengkap atau pendukung kegiatan wisata, yang berdasar pada letak zona ketiga yang terhubung langsung dengan ME utama. 


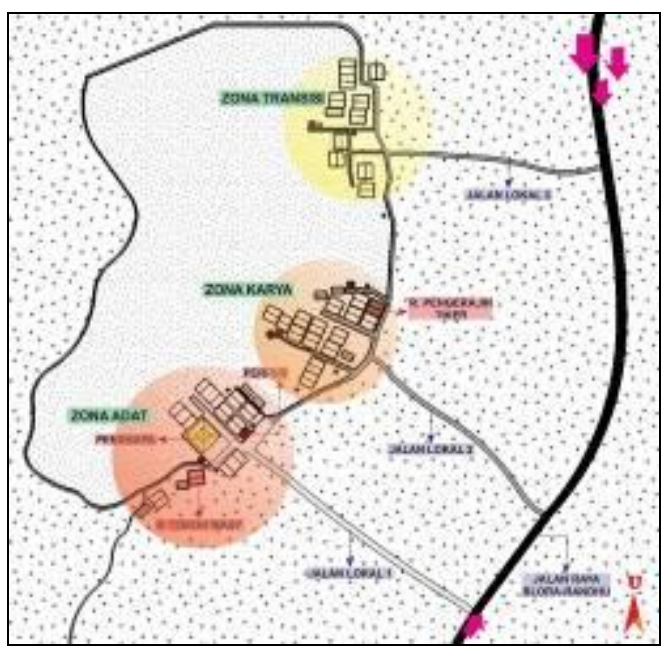

Gambar 3. Pembagian Zona dalam Kawasan Sumber : Dokumen Novita, 2017

4. Peletakan dan Tata Massa Bangunan dalam Kawasan

Peletakan bangunan berdasarkan fungsi, keterkaitan dengan bangunan lama/lingkungan, dan ketersediaan lahan. Tata massa bangunan bedasarkan pada hierarki tata massa bangunan Samin. Berikut pembahasan peletakan dan tata massa bangunan yang dikelompokkan berdasarkan zona :

Zona Adat

Fasilitas tambahan yang diletakkan pada zona adat dalah balai persiapan, perpustakaan, kandang ternak terpadu, dan WC umum.

Balai persiapan berfungsi sebagai tempat mempersiapkan kebutuhan upacara adat / pertunjukan yang dilaksanakan di pendhapa, sehingga balai persiapan diletakkan bersebelahan dengan pendhapa yaitu di sisi Barat Daya pendhapa Perpustakaan dengan fungsi utama pustaka memiliki peran dalam mendukung kegiatan pembelajaran di pendapa maka perpustakaan diletakkan di sisi Barat Daya pendhapa dan sisi Utara umah tokoh masyarakat, bersebelahan dengan balai persiapan. WC umum tambahan diletakkan di belakang pendhapa. Kandang ternak terpadu diletakkan di belakang pemukiman.

Balai persiapan memiliki bentuk dasar persegi panjang mengalami pengurangan di bagian sudut, sehingga memiliki dua pintu menuju pendhapa. Perpustakaan terdiri dari tiga persegi panjang yang disusun zigzag. Jarak kedua bangunan ke jalam $1 \mathrm{~m}$. Jarak antar kedua bangunan pada sisi samping 2,3 $\mathrm{m}$ dan bagian belakang 2,8 m, sedangkan jarak dengan bangunan lama sekitar 2,1 meter. Kandang ternak berbentuk persegi panjang, menghadap ke jalan kampung yang berada di sisi Timur Laut pendhapa. Jarak kandang dengan bangunan $10 \mathrm{~m}$. Jarak kandang dengan jalan 1 m. WC umum tambahan memiliki bentuk persegi menghadap ke arah pendhapa. Jarak WC dengan bangunan di sebelah WC,7 $\mathrm{m}$ dan jarak ke jalan $0.6 \mathrm{~m}$.

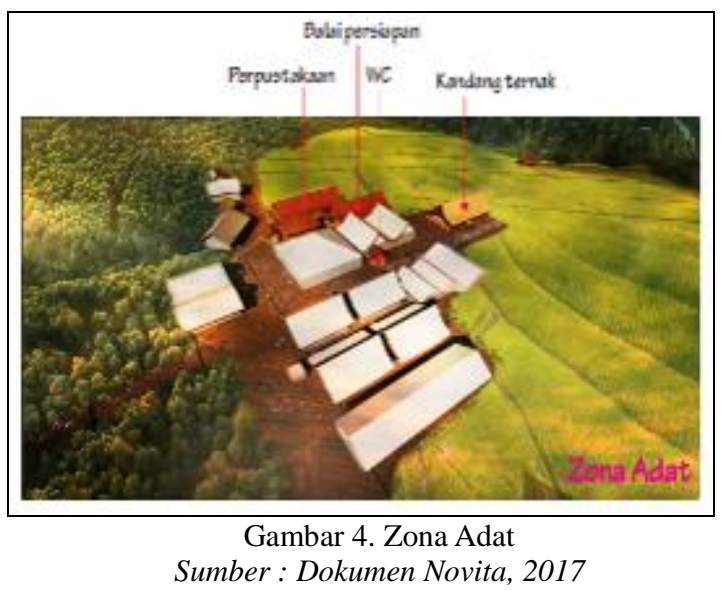

Zona Karya

Fasilitas tambahan yang diletakkan pada zona karya adalah sentra kerajinan, kandang ternak, rumah bibit, dan WC umum. Sentra kerajinan dengan kegiatan utama produksi kerajinan diletakkan diletakkan di seberang rumah pembuat tikar pandan. Rumah bibit dan kandang ternak terpadu diletakkan bersebelahan di sisi tenggara atau belakang pemukiman dan dekat dengan sawah. Saung-saung sebagai tempat pembelajaran bertani diletakkan di sepanjang jalan lingkar tepi sawah. WC umum ditambahkan pada ujung lorong tengah yang diperuntukkan untuk penduduk.

Sentra kerajinan menghadap ke jalan kampung dan rumah pembuat tikar pandan. Bentuk dasar sentra kerajinan terdiri dari tiga persegi panjang, yang dibagi menjadi tiga bagian agar tidak terlihat besar, karena di sekitarnya tidak ada bangunan besar. Jarak sentra kerajinan dengan bangunan lain sekitar 2,5-4 m, Jarak sentra kerajinan dengan jalan sekitar $8 \mathrm{~m}$. Rumah bibit juga menghadap ke arah jalan kampung. Bentuk rumah bibit sama dengan kandang ternak, yaitu persegi panjang dengan sisi pendek sebagai muka. Jarak rumah bibit dengan bangunan di dekatnya sekitar $7 \mathrm{~m}$, sedangkan jarak rumah bibit ke jalan sekitar $3 \mathrm{~m}$. Jarak kandang dengan jalan $1 \mathrm{~m}$ dan jarak kandang dengan pemukiman $10 \mathrm{~m}$. 


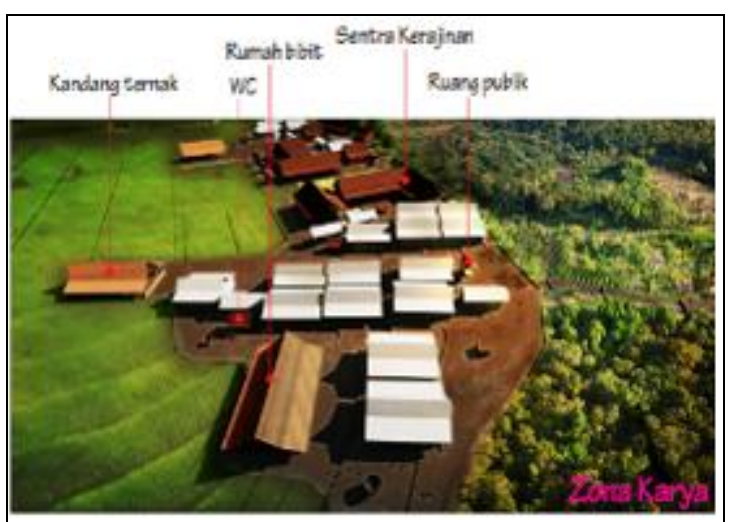

Gambar 5. Zona Karya

Sumber : Dokumen Novita, 2017

\section{Zona Transisi}

Fasilitas tambahan yang diletakkan pada zona transisi adalah pusat informasi, rumah makan, toko souvenir, penginapan, musholla, kandang ternak dan WC umum. Pusat informasi diletakkan pada sisi Selatan jalur masuk zona transisi, agar terlihat langsung oleh pengunjung. Rumah makan ditempatkan pada sisi Utara area masuk zona transisi. Toko souvenir berhadapan langsung dengan jalur masuk zona transisi sebagai penanda kawasan wisata. Penginapan diletakkan di dalam pemukiman namun tidak terlalu jauh dari jalur masuk 3. Musholla diletakkan di sisi Barat jalur penghubung antara zona transisi dan zona karya, serta dekat dengan penginapan. Kandang ternak diletakkan di belakang pemukiman. Penambahan WC umum diletakkan di sisi Selatan dan bersebelahan dengan musholla.

Penginapan penduduk terdiri atas tiga bagian, ketiga massa menghadap ke jalan kampung (Utara), bersebelahan dengan rumah penduduk, jarak penginapan dengan bangunan lain $3 \mathrm{~m}$ dan jarak bangunan ke jalan 2-9 m. Musholla menghadap ke arah Timur yaitu ke jalan penghubung antara cluster 3 dan 2. Bentuk dasar musholla adalah persegi. Musholla bersebelahan dengan rumah warga, jarak antar bangunan sekitar 3 meter. Pusat informasi menghadap ke jalur penghubung menuju zona karya. Bentuk dasar bangunan persegi panjang dengan sisi panjang sebagai muka. Tidak ada bangunan di sisi pusat informasi, jarak bangunan dengan jalan $1 \mathrm{~m}$. Toko souvenir menghadap Barat ke arah jalur masuk cluster 3 yang termasuk jalan penghubung. Tidak ada bangunan di sekitar toko, jarak bangunan dengan jalan sekitar 1-2 meter. Rumah makan menghadap ke jalur penghubung. Bentuk dasar bangunan persegi panjang dengan sisi Selatan yang miring mengikuti bentuk lahan. Tidak ada bangunan yang bersebelahan, jarak bangunan dengan jalan $1.5 \mathrm{~m}$. Kandang ternak menghadap ke jalan kampung dengan jarak sekitar $1 \mathrm{~m}$, sedangkan jarak kandang ternak dengan perumahan warga $10 \mathrm{~m}$. Tambahan WC umum menghadap ke jalur penghubung antar cluster dengan jarak WC dan musholla sekitar $3 \mathrm{~m}$.

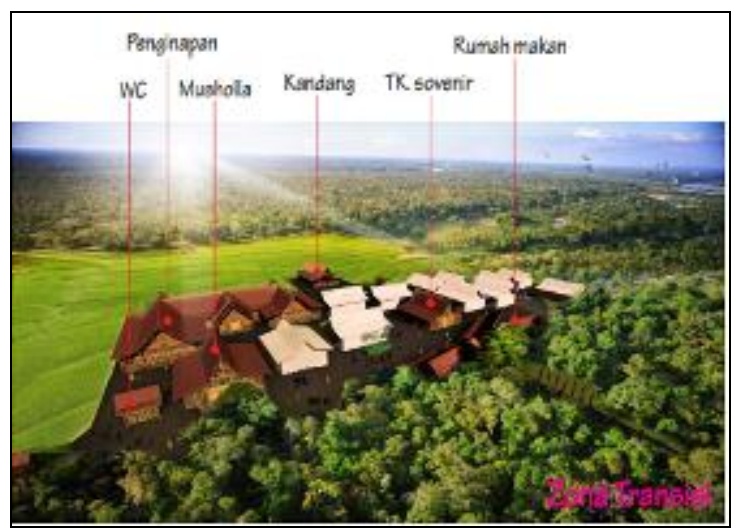

Gambar 6. Zona Transisi

Sumber : Dokumen Novita, 2017

Berikut skema peletakan dan tata massa bangunan dalam kawasan secara keseluruhan :

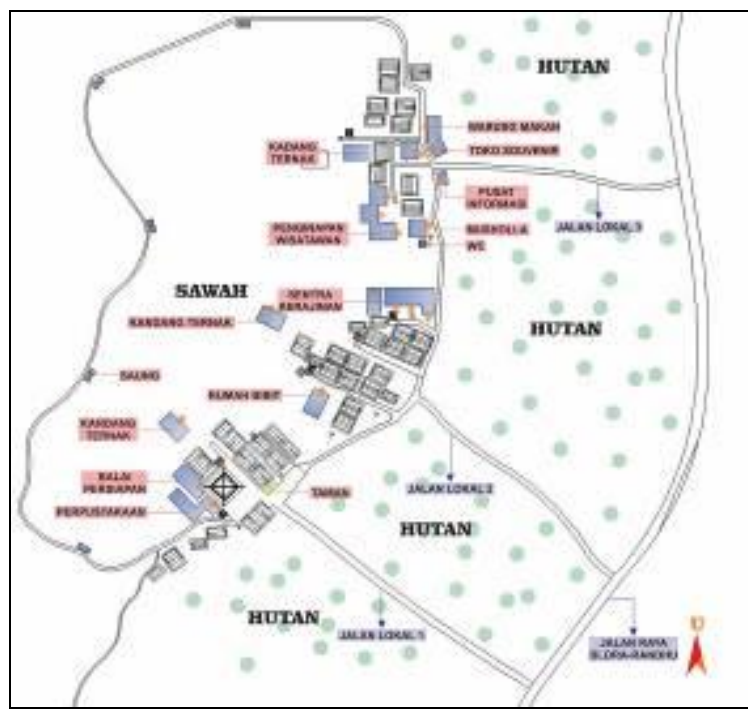

Gambar 7. Peletakan dan Tata Massa Bangunan dalam Kawasan

Sumber : Dokumen Novita, 2017

\section{Penambahan Jalur Sirkulasi/Kawasan}

Pada kawasan Samin terdapat tiga penambahan jalan. Penambahan jalan 1 terletak pada zona adat, merupakan penambahan panjang jalan sisi Timur Laut pendhapa dengan panjang $20 \mathrm{~m}$ dan lebar $3 \mathrm{~m}$ mengikuti lebar jalan awal. 
Penambahan jalan 2 terletak pada zona karya, merupakan penambahan panjang jalan tengah pada zona karya dengan panjang $8 \mathrm{~m}$ dan lebar 3,5 m. Penambahan jalan 3 terletak pada zona transisi, merupakan penambahan jalan di depan penginapan, dengan panjang $25 \mathrm{~m}$ dan lebar 1,5 meter. Penambahan jalan 4 terletak di zona transisi, merupakan penambahan jalan paling utara zona transisi, sebagai jalur menuju kandang ternak dengan panjang 29,5 $\mathrm{m}$ dan lebar $1,5 \mathrm{~m}$.

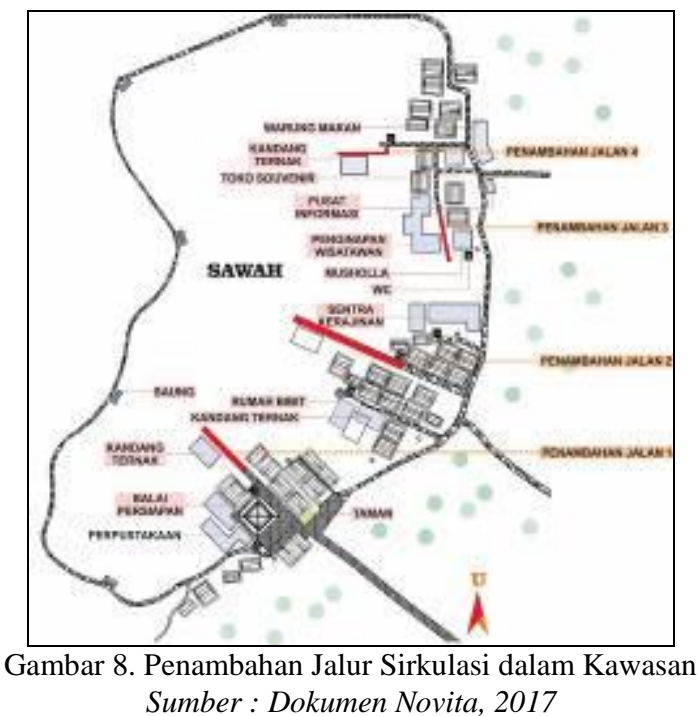

\subsection{Perancangan Bangunan}

Perancangan bangunan terdiri dari komponenkomponen pembentuk bangunan lama yang terdiri dari kepala, badan, dan kaki berdasarkan filosofi bangunan Jawa.

\section{Kepala}

Kepala pada bangunan adalah atap.

Bentuk atap didominasi oleh bentuk bekok lulang, dengan enam varian atap yang terdiri dari tiga bentuk atap lama dan tiga bentuk atap baru. Bentuk atap lama terdiri dari : bekok lulang asli, bekok lulang pelana, dan bekok lulang dengan tambahan tritisan.

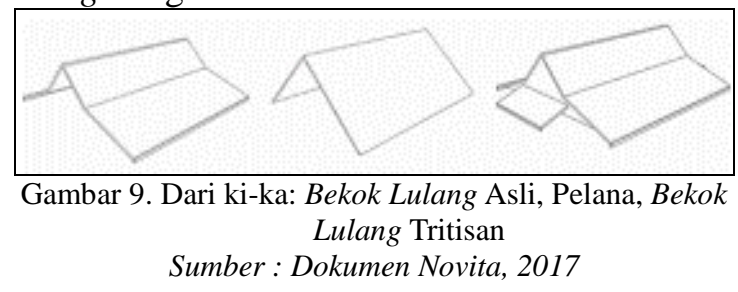

Atap bekok lulang asli digunakan untuk : kendang ternak, rumah bibit, saung, ruang publik dan penginapan. Atap pelana digunakan untuk : WC umum dan pusat informasi. Atap bekok lulang dengan tritisan digunakan untuk balai persiapan.

Bentuk atap baru yaitu bekok lulang bertingkat, atap menerus, dan bekok lulang pisah.

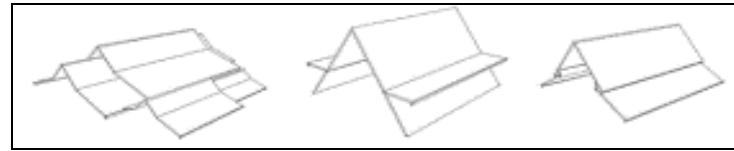

Gambar 10. Dari ki-ka: Bekok Lulang Bertingkat, Menerus, Pisah

Sumber : Dokumen Novita, 2017

Atap bekok lulang bertingkat digunakan untuk perpustakaan. Atap menerus digunakan untuk musholla dan toko souvenir. Atap bekok lulang pisah digunakan untuk sentra kerajinan dan rumah makan.

Struktur atap secara garis besar dibedakan menjadi tiga yaitu struktur atap bekok lulang asli, menerus, dan pisah. Struktur atap bekok lulang asli merupakan struktur asli, yang digunakan pada bangunan di kawasan Samin. Struktur atap menerus yaitu kuda-kuda atap diteruskan menjadi kolom tengah bangunan. Struktur atap pisah hampir sama dengan asli, hanya saja setengah kuda-kuda pada sisi kiri kanan tidak menyambung dengan kuda-kuda utuh, tapi agak ke bawah bertumpu pada kolom.

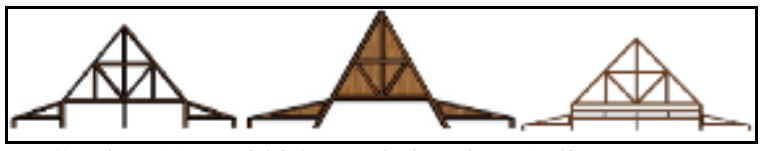

Gambar 11. Dari ki-ka: Bekok Lulang Asli, Menerus, Bekok Lulang Pisah

Sumber : Dokumen Novita, 2017

Material yang digunakan untuk struktur atap adalah kayu jati, dan penutup atap menggunakan genting. Tidak ada ornamen pada atap hanya berfokus pada bentuk dan struktur 1. Badan

Badan pada bangunan adalah bagian tengah bangunan dimana terdiri dari dinding dan bukaan.

Terdapat tiga macam dinding yang berdasar pada macam dinding bangunan Samin yaitu dinding tertutup, semi terbuka, dan terbuka. Dinding tertutup digunakan untuk bangunan yang membutuhkan privasi dan ketenangan. Pada fasilitas baru dinding tertutup digunakan untuk perpustakaan, balai persiapan, pusat informasi, penginapan dan musholla. 


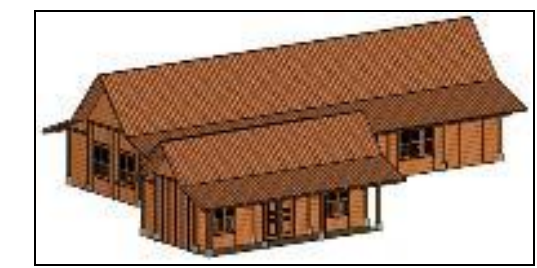

Gambar 12. Bangunan dengan Dinding Tertutup Sumber : Dokumen Novita, 2017

Dinding semiterbuka digunakan untuk bangunan komersil atau mempunyai kegiatan dengan sifat memamerkan untuk menarik kedatangan pengunjung. Pada fasilitas baru dinding semi terbuka digunakan untuk sentra kerajinan, toko souvenir, rumah makan, dan WC.

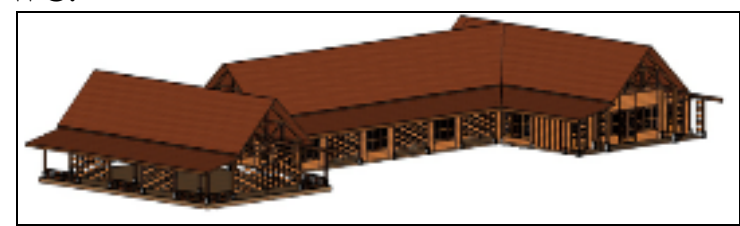

Gambar 13. Bangunan dengan Dinding Semi Terbuka Sumber : Dokumen Novita, 2017

Dinding terbuka digunakan untuk bangunan publik yang bersifat interaktif dan rekreatif. Pada fasilitas baru dinding terbuka digunakan untuk rumah bibit, kandang ternak, ruang publik, dan saung.

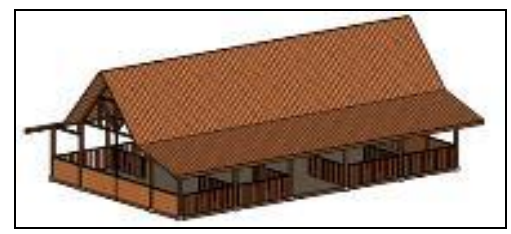

Gambar 14. Bangunan dengan Dinding Terbuka Sumber : Dokumen Novita, 2017

Struktur tengah yaitu kolom hanya terdiri dari dua macam, yaitu kolom tegak yang digunakan pada hampir semua bangunan, dan kolom miring sebagai bagian dari atap menerus yang digunakan pada musholla dan toko souvenir.

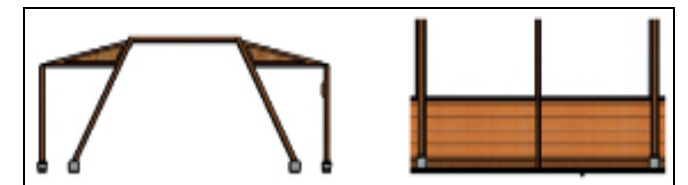

Gambar 15. Dari ki-ka: Kolom Menerus dan Kolom Tegak

Sumber : Dokumen Novita, 2017
Bukaan terdiri dari pintu, jendela, dan ventilasi. Bentuk ketiga bukaan berdasar pada bentuk bukaan rumah masyarakat Samin. Terdapat dua jenis variasi bukaan yaitu bukaan tanpa ornamen dan menggunakan ornamen. Bukaan dengan ornamen digunakan untuk bangunan komersil yaitu sentra kerajinan, rumah makan, dan toko souvenir; sedangkan bangunan lain menggunakan bukaan tanpa ornamen.

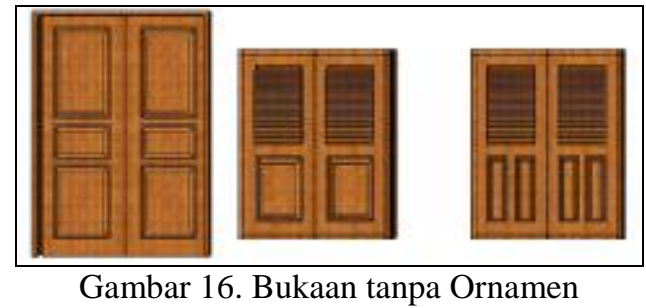

Sumber : Dokumen Novita, 2017

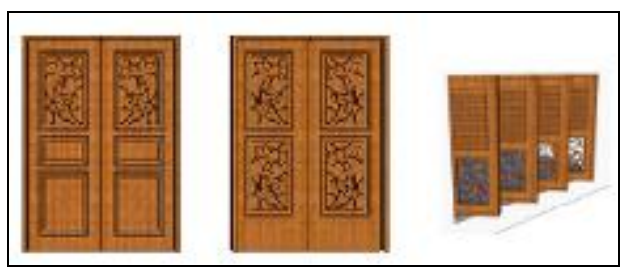

Gambar 17. Bukaan dengan Ornamen Sumber : Dokumen Novita, 2017

Material yang digunakan untuk semua bagian badan bangunan adalah kayu jati. Ornamen yang digunakan pada badan terdapat dua jenis, yaitu pola papan kayu yang berdasar pada penyusunan papan untuk dinding bangunan, yang diberi bukaan dan ukiran sulur yang berdasar pada motif batik Samin.

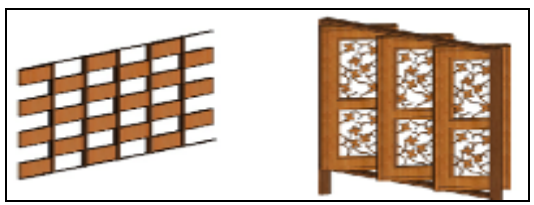

Gambar 18. Dari ki-ka: Ornamen Pola Papan dan Ukiran Sulur

Sumber : Dokumen Novita, 2017

2. Kaki

Kaki pada bangunan adalah bagian bawah bangunan yaitu lantai dan pondasi (bangunan 
menggunakan umpak). Lantai bangunan menggunakan susunan bata dan tanah asli. Sedangkan umpak menggunakan batu yang memiliki beberapa bentuk yaitu umpak persegi digunakan untuk : kandang, rumah bibit, WC, saung, ruang publik, dan pusat informasi; umpak balok diguakan untuk : perpustakaan, penginapan, dan balai persiapan; umpak balok dengan ukiran digunakan untuk : sentra kerajinan, toko souvenir dan rumah makan; umpak lingkaran digunakan untuk musholla dan toko souvenir.

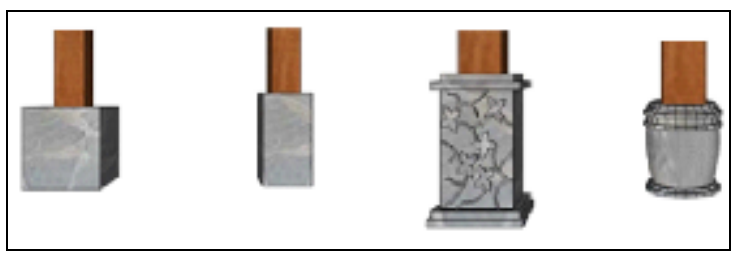

Gambar 19. Dari ki-ka: Umpak persegi, balok, balok dengan ornamen, dan lingkaran

Sumber : Dokumen Novita, 2017

Berikut pengaplikasian seluruh komponen bangunan pada toko souvenir :

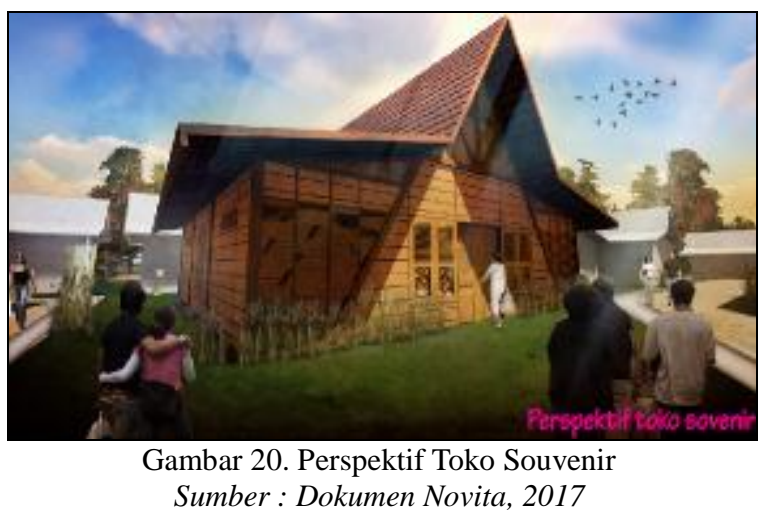

\subsection{Utilitas Kawasan}

Utilitas kawasan berfokus pada instalasi air yang terdiri dari air bersih dan air kotor serta penerangan lingkungan.

1. Instalasi Air Bersih

Air bersih pada kawasan Dukuh Karangpace bersumber dari PDAM dan sumur, sumber air utama berasal dari PDAM dengan sistem komunal, dipusatkan pada tandon-tandon air sebagai wadah air cadangan jika air PDAM mati. Air dari PDAM pertama dialirkan ke tandon-tandon air, setelah tandon penuh, air akan dialirkan ke rumah-rumah warga dan WC umum.

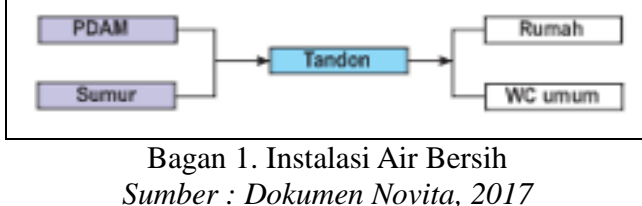

2. Instalasi Air Kotor

Intalasi air kotor terdiri dari septic tank untuk limbah padat dan water treatment untuk pengolah limbah cair. Septic tank dan water treatment digunakan secara komunal dan diletakkan di belakang pemukiman, karena tidak memungkinkan diletakkan pada setiap rumah warga, mengingat jarak antar bangunan yang sangat dekat. Limbah khusus seperti limbah batik dan kotoran ternak akan memiliki pengolahan khusus kotoran ternak, agar tidak mencemari lingkungan. Kotoran ternak diolah menjadi biogas dan pupuk kandang yang dapat mendukung pertanian organik.

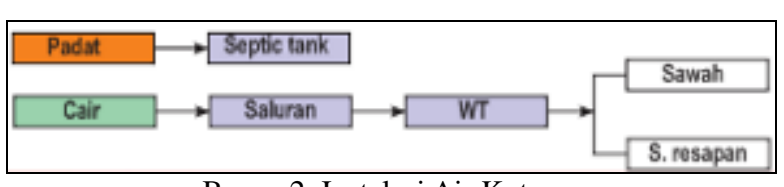

Bagan 2. Instalasi Air Kotor

Sumber : Dokumen Novita, 2017

3. Instalasi Listrik / Penerangan lingkungan Lampu jalan dan lampu obor akan diletakkan pada jalan-jalan dalam kawasan Samin. Lampu jalan dengan daya besar diletakkan pada jalurjalur masuk menuju pemukiman. Desain lampu jalan merupakan lampu klasik dengan material bambu, terdiri dari tiang bambu dan kap lampu klasik untuk memberikan kesan tradisional. Tinggi lampu jalan sekitar 2,5 m. Jarak antar lampu 8-10 m.

Lampu obor dengan daya kecil akan diletakkan di sepanjang jalan lingkar desa sebagai penerangan saat kirab, serta pada lorong-lorong rumah warga. Lampu obor terbuat dari bilah bambu yang disusun melingkar, dan diletakkan lampu di dalam lingkaran bilah bambu. Tinggi lampu obor kurang lebih 1,2 m. Jarak antar lampu 3-4 m. 


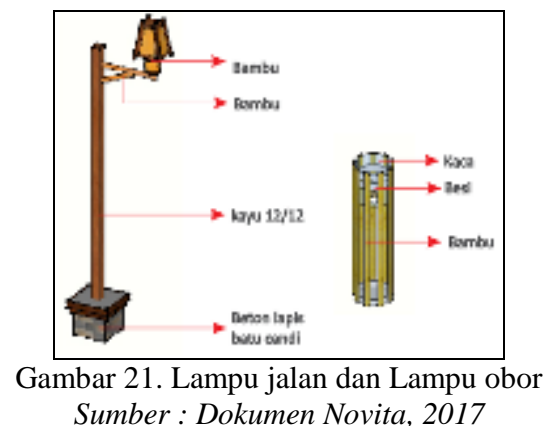

Berikut peletakan utilitas dalam kawasan:

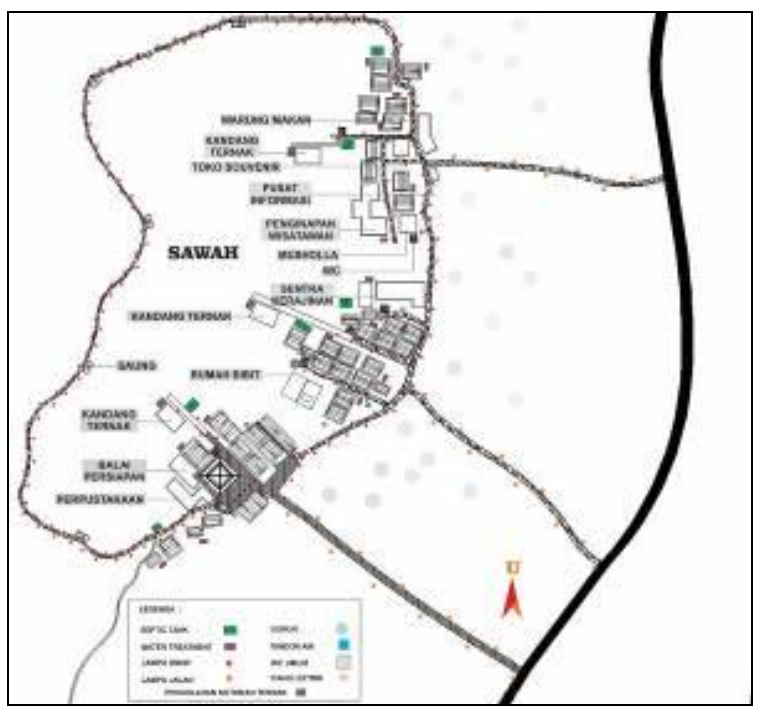

Gambar 22. Peletakan Utilitas dalam Kawasan Sumber : Dokumen Novita

\section{KESIMPULAN}

Arsitektur kontekstual diterapkan dalam Kawasan wisata Budaya Samin, dengan meminimalisir perubahan konfigurasi spasial dan keadaan lingkungan kawasan untuk perancangan tapak, serta memasukkan elemenelemen visual bangunan lama ke dalam bangunan baru untuk perancangan bangunan, dengan tujuan mempertahankan otentitas kawasan. Perancangan bangunan dan kawasan berpedoman pada elemen-elemen visual arsitektur kontekstual, yang dipadu dengan hierarki dalam lingkungan Samin, sehingga diperoleh prinsip desain Arsitektur Samin. Telah disebutkan pada pendahuluan, bahwa terdapat sebelas elemen visual yang berpengaruh pada keserasian untuk mendapatkan kontinuitas visual, tiga elemen visual digunakan untuk perancangan tapak dan delapan untuk perancangan bangunan.
Perancangan tapak terdiri dari penataan lingkungan dan peletakan bangunan baru. Perancangan kawasan tidak mengubah lingkungan hanya terdapat beberapa penambahan yaitu perbaikan jalan, area parkir, beberapa jalan baru, dan utilitas kawasan. Peletakan bangunan baru berdasar pada tiga elemen visual yaitu:

- Jarak bangunan ke jalan sekitar 1 meter bahkan bangunan cenderung menempel dengan jalan.

- Jarak antar bangunan sekitar 2 meter baik samping maupun belakang bangunan

- Komposisi massa lama dan massa baru saling berdampingan, karena bangunan baru akan mengikuti bangunan lama.

Perancangan bangunan juga berdasar pada bangunan lama, dengan berpedoman pada 8 elemen visual yaitu :

- Ketinggian bangunan 3-4 m merupakan bangunan satu lantai

- Bentuk bangunan didominasi dengan bentuk bekok lulang dan tidak berpagar. Pendhapa merupakan bangunan yang memiliki bentuk berbedayaitu atap limasan dan dinding terbuka. Bangunan pendhapa merupakan landmark kawasan.

- Fasad bangunan (bekok lulang) terdiri dari atap dengan material genting, dinding dengan material kayu atau kulit kayu jati yang disusun horisontal, pintu dan jendela/ventilasi, kolom kayu, dan pondasi umpak dengan material batu.

- Pintu terdiri dari dua bagian, pintu terluar berbentuk menyerupai pagar dan bagian kedua berupa papan. Bentuk jendela terdiri dari lubang jendela dan dua sisi daun jendela berjenis jalusi. Ventilasi lebih banyak digunakan daripada jendela, berupa lubang pada dinding.

- Terdapat dua pintu dalam bangunan Samin, pintu utama di fasad depan dan pintu servis di fasad belakang. Jendela hanya terdapat pada fasad depan, sedangkan pada sisi samping dan belakang hanya menggunakan ventilasi.

- Sebagian besar material bangunan baik fasad maupun struktur bangunan menggunakan kayu jati, dengan genting sebagai penutup atap. Material lantai menggunakan tanah padat, susunan bata, atau batu alam.

- Warna bangunan menggunakan warna-warna alami dari material yang digunakan. 
- Skala bangunan terhadap manusia pada kawasan Samin cenderung intim, sesuai dengan prinsip kekeluargaan pada masyarakat Samin.

\section{REFERENSI}

Alsayyad, N. (2001). Consuming Tradition, Manufacturing Heritage Global Norms and Urban Forms in the Age of Tourism.

Brolin, B. C. (1980). Architecture in Context. New York: Van Nostrand Reinhold Company.

DPPKKI. (2014). Data Infrastruktur Sistem Informasi Pembangunan Daerah Kabupaten Blora.

Koentjaraningrat. (1990). Pengantar Ilmu Antropologi. Jakarta: Rineka Cipta.

Lynch, K. (1960). The Image of the City. Cambridge, United States of America: The Technology Press \& Harvard University Press.

Setiono, A. (2011). Ensiklopedia Blora Alam, Budaya, dan Manusia. Buku 6 Pariwisata dan Kuliner. Blora: Yayasan untuk Indonesia, The Heritage Society, Blora Pride Foundation.

Sudarwani, M. M. (2016). Laporan Penelitian: Pola Tata Ruang Kawasan Permukiman Kampung Naga di Tasikmalaya.

UU No. 10. Kawasan Strategis Pariwisata (2009).

Sardjono, D. N. (2013). Tenganan, Desa yang Menjaga Kearifan Lokal _ Majalah Griya Asri.

Direktori Wisata Indonesia. (2016). Wisata Kampung Naga, Garut _ Direktori Wisata Indonesia.

Harian Jateng. (2015). Wisata Kampung Samin Surosentiko Blora Jawa Tengah _ Harian Jateng.

Kumurur, V. A., \& Damayanti, S. (2009). Pola perumahan dan pemukiman desa tenganan bali, 1(1), 1-7.

Sumber Website :

loketpeta.pu.go.id. (2012). Peta Infrastruktur Kabupaten Blora (2012) _ Loket Peningkatan Pelayanan Informasi Peta.

m.tempo.co. (2016). Kampung Naga, Kembalikan Anda ke Peradaban Lampau travel_trip_tempo.

penataanruangjateng.info. (2016). Layanan
Informasi Penataan Ruang Provinsi Jawa Tengah.

travel.kompas.com. (2014). Melihat Bali Sesungguhnya di Desa Tenganan Kompas.

travel.kompas.com. (2017). Kampung Naga,

Kearifan di Bawah Tebing - Kompas.

wisatabaliutara.com. (2015). Desa Penglipuran -

Desa Wisata Tradisional Adat Bali.

www.blorakab.go.id. (2016). Pemerintah

Kabupaten Blora

Sumber Wawancara :

BAPPDEDA Kabupaten Blora. (2015). Rencana Pembangunan Kampung Samin. Blora.

Lasio. (2015). Komunitas Samin. Blora.

Widodo. (2015). Keadaan Masyarakat Samin Saat Ini. Blora. 